\title{
Task Conflict and Task Control: A Mini-Review
}

\author{
Ran Littman ${ }^{1 * t}$, Eldad Keha ${ }^{1,2 \dagger}$ and Eyal Kalanthroff ${ }^{1}$ \\ 'The Clinical Neuropsychology Laboratory, Department of Psychology, The Hebrew University of Jerusalem, Jerusalem, \\ Israel, ${ }^{2}$ Department of Psychology, Achva Academic College, Arugot, Israel
}

Stimulus-driven behaviors are triggered by the specific stimuli with which they are associated. For example, words elicit automatic reading behavior. When stimulus-driven behaviors are incongruent with one's current goals, task conflict can emerge, requiring the activation of a task control mechanism. The Stroop task induces task conflict by asking participants to focus on color naming and ignore the automatic, stimulus-driven, irrelevant word reading task. Thus, task conflict manifests in Stroop incongruent as well as in congruent trials. Previous studies demonstrated that when task control fails, reaction times in congruent trials slow down, leading to a reversed facilitation effect. In the present mini-review, we review the literature on the manifestation of task conflict and the recruitment of task control in the Stroop task and present the physiological and behavioral signatures of task control and task conflict. We then suggest that the notion of task conflict is strongly related to the concept of stimulus-driven behaviors and present examples for the manifestation of stimulus-driven task conflict in the Stroop task and additional tasks, including object-interference and affordances tasks. The reviewed literature supports the illustration of task conflict as a specific type of conflict, which is different from other conflict types and may manifest in different tasks and under diverse modalities of response.

Keywords: Stroop task, cognitive control, executive functions, task conflict, task control, stimulus-driven behavior

The concept of cognitive control refers to a set of abilities which allow for the effortful application and maintenance of goal-directed behaviors (Banich, 2009; Diamond, 2013). For several decades, the Stroop task has been serving as a principal tool for investigating cognitive control in the lab (MacLeod, 1991). In the present mini-review, we focus on a unique feature of cognitive control, task control, and its recruitment for the resolution of a specific type of conflict - task conflict. We first review the literature of Stroop task conflict, illustrate task conflict's physiological and behavioral signature and then move to describe task conflict in the context of stimulus-driven behaviors, refer to its manifestation in other tasks and under diverse modalities of response, and suggest that impaired task control may be related to certain pathological behaviors. 


\section{TASK CONFLICT IN THE STROOP TASK}

In various situations, individuals must decide between two alternative task demands. Such circumstances often result in the emergence of task conflict. Task conflict has been studied mainly by using the Stroop task (Stroop, 1935) in which participants are instructed to name the ink-color of congruent (e.g., RED written in red), incongruent (e.g., RED written in blue), and non-word neutral (e.g., XXXX written in red) stimuli while ignoring the word's meaning (MacLeod, 1991). The typical Stroop reaction time (RT) data show a robust Stroop interference effect (incongruent RT > neutral RT) and a smaller and less robust Stroop facilitation effect (congruent RT < neutral RT). Goldfarb and Henik (2007) suggested that the Stroop task consists of two separate conflicts - an information conflict between the incongruent word and ink color, which manifests in incongruent trials because of the incongruency between taskrelevant and task-irrelevant information (e.g., blue and red); and a task conflict between the relevant color-naming task and the irrelevant, stimulus-driven word-reading task, which manifests in incongruent as well as in congruent trials because words trigger an automatic tendency to read (also see Rogers and Monsell, 1995; MacLeod and MacDonald, 2000; Levin and Tzelgov, 2016b; Kalanthroff et al., 2018a). Thus, while Stroop incongruent trials consist of both information conflict and task conflict, Stroop congruent trials consist of task conflict and not information conflict. Accordingly, the RT difference between non-word neutrals (which serve as a conflict-free baseline of general performance) and congruent conditions commonly serves as a measure of task conflict (Goldfarb and Henik, 2007; Kalanthroff et al., 2018a). Dissociation between the two conflicts was demonstrated by their diverse patterns of brain activation (Aarts et al., 2009; Desmet et al., 2011; Elchlepp et al., 2013) and their reflection in different components of an ex-Gaussian distribution (Steinhauser and Hübner, 2009; also see Aarts et al., 2009; Moutsopoulou and Waszak, 2012; Shahar and Meiran, 2015). These findings support the existence of task conflict as a specific type of conflict that is dissociated from other conflict types.

\section{PHYSIOLOGICAL SIGNATURE OF TASK CONFLICT AND TASK CONTROL}

The resolution of task conflict is managed by the activation of a task control mechanism (Entel et al., 2015; Kalanthroff et al., 2018a; Schuch et al., 2019). Neuroimaging studies have shown that the anterior cingulate cortex (ACC) - a brain area that is involved in conflict monitoring (Carter et al., 1998, 1999; Botvinick et al., 1999, 2004; Bush et al., 2000; Braver et al., 2001; Kerns et al., 2004) is more active, not only when contrasting incongruent Stroop trials to non-word neutrals but also when contrasting congruent trials to non-word neutrals (Bench et al., 1993; Carter et al., 1995; Milham et al., 2002; Aarts et al., 2009).

Recent neuroimaging studies have provided evidence for the locus of task control in the brain. These studies have manipulated task conflict by using a word-arrow version of the Stroop task (Aarts et al., 2009) or by manipulating the proportion of congruent, incongruent, and neutral trials within Stroop blocks (Grandjean et al., 2012, 2013), a manipulation that reduces or enhances task control (see below). The data from these studies (Aarts et al., 2009; Grandjean et al., 2012, 2013) support the idea that task conflict results in activation of the ACC, the medial superior frontal gyrus (MFC), and ventral areas of the lateral prefrontal cortex (L-PFC). Subsequently, the resolution of task conflict is reflected by an involvement of the dorsal part of the L-PFC (DL-PFC), which marks the top-down monitoring processes of favoring the relevant task and the implementation of task demands (MacDonald et al., 2000; Egner and Hirsch, 2005; Carter and Van Veen, 2007; Brosnan and Wiegand, 2017). Additional findings marked the differences in brain activation in the face of task conflict and information conflict. While both conflicts activated the ACC and the MFC, information conflict was associated with activity in ventral L-PFC, whereas task conflict activated both ventral and dorsal regions (Aarts et al., 2009).

Other studies have employed Stroop tasks while scrutinizing changes in pupil dilation, which has been used as a measure of effort extraction and the employment of cognitive control (Kahneman and Beatty, 1966; for reviews see Beatty and LuceroWagoner, 2000; Laeng et al., 2012; Sirois and Brisson, 2014; van der Wel and van Steenbergen, 2018). These studies provided evidence for interference and facilitation effects, measured by pupil dilation (Brown et al., 1999; Siegle et al., 2004, 2008; Laeng et al., 2011; Hasshim and Parris, 2015). Recently, Hershman and Henik (in press) reported a dissociation between task conflict and information conflict by measures of pupil dilation. Specifically, participants' pupils became dilated when observing both congruent and incongruent trials in comparison to non-word neutrals at about $500 \mathrm{~ms}$ after the stimulus onset. A second dilation became evident for incongruent trials only at about $900 \mathrm{~ms}$ after the stimulus onset. These data show that the emergence of task conflict (and the recruitment of task control) precedes the emergence of information conflict and support previous suggestions after which the presentation of two task sets lead to the emergence of task conflict even before information regarding stimulus' identity of dimensions begins to compute (MacLeod and MacDonald, 2000; Monsell et al., 2001; Goldfarb and Henik, 2007; Steinhauser and Hübner, 2009; Braverman et al., 2014).

\section{BEHAVIORAL SIGNATURE OF TASK CONFLICT AND TASK CONTROL}

The physiological evidence for the emergence of task conflict in Stroop congruent trials appears to stand in contradiction with behavioral findings, which indicate that responses to congruent trials are often faster than to neutral trials. It has been suggested (Goldfarb and Henik, 2007; Kalanthroff et al., 2018a) that in healthy adults, task control is highly efficient and leads to a rapid resolution of task conflict. Hence, task conflict is not behaviorally observable under standard conditions 
but can be seen under specific conditions, yielding in Stroop reverse facilitation (RF; faster responses to neutral stimuli than to congruent stimuli), which serves as the behavioral signature of task conflict (Kalanthroff et al., 2018a). For example, to illustrate Stroop RF, several studies have manipulated the proportion of congruent, incongruent, and neutral trials, creating blocks that consist of a majority or a minority of non-word neutrals, a manipulation that reduces or enhances task control, respectively, as participants mostly encounter non-conflictual or conflictual trials (Tzelgov et al., 1992; Goldfarb and Henik, 2007; Kalanthroff et al., 2013c; Entel et al., 2015; Shichel and Tzelgov, 2018). Other studies presented a cue that indicated whether the following trial will be conflictual or not (Goldfarb and Henik, 2007), have manipulated the length of the responsestimulus interval (RSI; Parris, 2014), or combined the Stroop task with additional measures of working memory (Kalanthroff et al., 2015), inhibitory control (Kalanthroff and Henik, 2013; Kalanthroff et al., 2013b), and task switching (Kalanthroff and Henik, 2014). The accumulating evidence from these studies shows that, when task control is overloaded, or, alternatively, when task control is reduced and "put to sleep," Stroop RF, signifying the behavioral marker of task conflict, becomes evident (however see Augustinova et al., 2018, for different results when using an RSI procedure). Recently, Kalanthroff et al. (2018a) have presented a computational model of the Stroop task, the proactive control/task conflict (PC-TC) model, which illustrates the resolution of task conflict and its modulation by task control (Figure 1). This model extends a previous model of the Stroop task (Botvinick et al., 2001) by accounting for the effects of task conflict and predicting RF. Behavioral evidence of task conflict was also demonstrated in task-switching paradigms (Braverman and Meiran, 2010; Schneider, 2015; Bugg and Braver, 2016), where a cue indicates which of two pre-determined tasks the participant needs to execute during a given trial. Unlike the Stroop task, in task-switching paradigms both tasks are relevant to some extent and the controlled process of favoring the relevant task cannot be prepared in advance.

The evidence discussed above illustrates task control as a specific type of cognitive control mechanism, which is recruited to resolve a specific type of conflict, task conflict. In the following section, we suggest that the emergence of task conflict and the recruitment of task control are strongly related to the concept of stimulus-driven behaviors.

\section{TASK CONFLICT IN THE CONTEXT OF STIMULUS-DRIVEN BEHAVIORS}

Stimulus-driven behaviors are triggered by the specific stimuli with which they are associated (Monsell, 2003; Waszak et al., 2003; Koch and Allport, 2006; Reuss et al., 2011; GanorMoscovitz et al., 2018; Hochman et al., 2018). This concept has been widely investigated outside the scope of the taskcontrol framework, and it echoes the findings of instrumental conditioning in animal studies: After an association between a stimulus and an action was established, animals were shown to keep responding to the stimulus even when it no longer

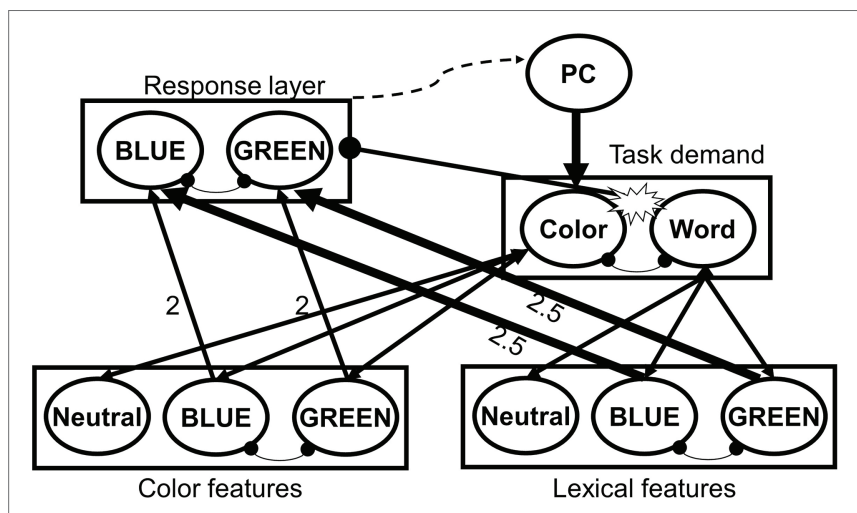

FIGURE 1 | Architecture of the proactive control/task conflict (PC-TC) model of the Stroop task. From Kalanthroff et al., 2018a, p. 2. Copyright 2018 by American Psychological Association. Reprinted with permission from American Psychological Association. In this model, task control is considered a proactive, effortful process that deploys control in advance of the stimulus for the resolution of conflict (De Pisapia and Braver, 2006; Braver et al., 2007; Barch and Ceaser, 2012; Braver, 2012). Pointy-headed arrows represent excitatory connections, whereas the round-headed arrows represent inhibitory connections. A stimulus activates its color and lexical representations in the input (features) layers. The activations from the input layers propagate to the response layer and to the task demand layer, which feeds back to the input layers. Congruent and incongruent color words, but not (non-word) neutral stimuli, activate both task demand units, which lead to task conflict. This task conflict inhibits the response layer, thereby slowing down responses to color words and resulting in Stroop reverse facilitation effect. When proactive control is high, attention is sufficiently biased in a top-down manner to the color-naming task demand unit, thus preventing (or rapidly resolving) task conflict and resulting in Stroop facilitation effect. However, manipulations that reduce proactive control lead to a stronger capture of attention by the irrelevant task dimension (word meaning), resulting in a reverse facilitation effect. This process takes place in both congruent and incongruent trials. In incongruent trials, an additional information conflict takes place when both input layers provide contradictory information (e.g., blue in the color features and green in the lexical features), leading to the activation of the two (mutually inhibitory) response units in the response layer, which causes the slowing down of reaction time and result in a (robust) Stroop interference effect.

predicted a reward and demonstrated spontaneous recovery of the stimulus-response (S-R) association even after undergoing extinction (Graham and Gagné, 1940; Guttman, 1953; Skinner, 1953; Rescorla, 1993; Bouton, 2004). In humans, several studies have demonstrated the automatic triggering of response activation processes when facing stimuli which were associated with certain responses, even when these responses were not eventually executed (Osman et al., 1992; De Jong et al., 1994; Eimer, 1995; Valle-Inclán, 1996; Gibbons and Stahl, 2008; also see Rothermund et al., 2005).

The concept of S-R binding is relevant to the processes taking place in the Stroop task (Mordkoff, 1996; Schmidt et al., 2007; Schmidt and Besner, 2008), where words elicit automatic reading behavior, even without an explicit intention to read (MacLeod and MacDonald, 2000; Monsell et al., 2001; Perlman and Tzelgov, 2006; Augustinova and Ferrand, 2014). Consequently, when the stimulus-driven reading behavior is incongruent with one's current goals, task conflict between stimulus-driven and goal-directed behaviors emerges, requiring the activation of a 
task control mechanism for the resolution of conflict (Kalanthroff et al., 2018a). Hence, in both congruent and incongruent Stroop conditions, stimulus-driven task-irrelevant word reading is incongruent with the relevant task of color naming, leading to the emergence of task conflict. Importantly, interference due to task conflict can manifest as long as the stimulus can be read, regardless of whether it is color related or not (Levin and Tzelgov, 2014, 2016a). Hence, non-color word neutrals (e.g., CHAIR in red) and pseudo words (e.g., HIX) also trigger the stimulus-driven reading behavior and result in the emergence of task conflict (Monsell et al., 2001; Goldfarb and Henik, 2007; Kinoshita et al., 2017; Kalanthroff et al., 2018a). The following examples illustrate the manifestation of stimulusdriven task conflict in different tasks and under diverse modalities of response in addition to the Stroop task.

Following the notion that form-based object-naming and classification is habitual and automatic in children (Kagan and Lemkin, 1961; Siegel and Vance, 1970; Bloom, 2002; Diesendruck and Bloom, 2003), Prevor and Diamond (2005) have used a color-object Stroop task, asking young children to name the colors of abstract shapes and familiar objects, which were presented in their congruent (e.g., a yellow banana), incongruent (e.g., a blue banana), or neutral (e.g., a purple scissors) colors. Because of their stimulus-driven tendency to name the objects, children were slower and less accurate in naming the color of namable objects in comparison to abstract forms, even when the objects appeared in their congruent colors. In a series of studies, La Heij and colleagues have replicated and elaborated these findings (La Heij et al., 2010; La Heij and Boelens, 2011, 2013; also see Starreveld and La Heij, 2017). Specifically, the authors demonstrated that the "object-interference effect" manifests due to the competition between the task set of color naming and the children's stimulus-driven prepotent tendency to name the object and not by other types of conflicts, such as lexical-based response conflict (La Heij et al., 2010; La Heij and Boelens, 2011). These findings implicate a stimulus-driven task conflict, which resembles the task conflict taking place in the Stroop task, manifesting in children who are unable to read.

Recently, we have investigated the emergence of task conflict in an affordance task. According to Gibson's (1979) theory of affordances, a common manipulatable object may trigger a response that has acquired a strong association with it (Rogers and Monsell, 1995; Allport and Wylie, 2000). Thus, simply viewing a manipulatable object triggers automatic and specific motor plans for interacting with it, even in the absence of an explicit intention for interaction (Vainio et al., 2008; Makris et al., 2013), as is evident by the automatic activation of the pre-motor cortex (Martin et al., 1996; Creem-Regehr and Lee, 2005; Beauchamp and Martin, 2007; Proverbio et al., 2011, 2013; Righi et al., 2014). In affordance tasks, participants are asked to classify objects (e.g., natural vs. manufactured) by responding with their left or right hand. The objects are presented as to trigger an automatic grabbing response in one hand (e.g., a cup with the handle turning rightwards), and the participants must suppress their automatic tendency of grabbing the object by its extended handle. Participants typically respond faster and more accurately when the relevant response (classifying the object) and the automatic, task-irrelevant response (grabbing the object) result in the activation of the same hand rather than different hands (Tucker and Ellis, 1998, 2004; Ellis and Tucker, 2000; Phillips and Ward, 2002; Tipper et al., 2006; Vainio et al., 2007; Pellicano et al., 2010). Recent data from our lab show that the resolution of task conflict in the Stroop task strongly predicted the resolution of conflict in the affordance task level (grab the object vs. classify the object), but not in the affordance response level (responding with the right hand vs. left hand; Littman \& Kalanthroff, manuscript in preparation). These findings link the emergence of stimulusdriven task conflict in both tasks, indicating the operation of a shared task control mechanism. As the Stroop task is based on linguistic skills and the affordance task calls for the activation of visuomotor abilities, these findings also illustrate the emergence of task conflict (and the recruitment of task control) in different tasks and under diverse modalities of response.

Recently, the conceptualization of task conflict as the result of stimulus-driven behaviors has proven to be an efficient framework for the understanding of several pathologies (Kalanthroff et al., 2018a). For example, it has been proposed that compulsivity in obsessive-compulsive disorder (OCD) may be strongly connected to excessive stimulus-response habit formation, rendering patients' capability of following elaborated environmental models in a manner that supports goal-directed behavior (Robbins et al., 2012; Kalanthroff et al., 2013a, 2018b; Gillan et al., 2014, 2015). In line with the task conflict framework, failure to suppress irrelevant stimulus-driven behaviors as a result of reduced task control functioning was suggested to be a pathological trait that also constitutes a core characteristic of the inability to suppress compulsive behaviors (Kalanthroff et al., 2017, 2018b). Following this line of study, interventions for the amelioration of task control abilities may prove useful for the enhancement of OCD patients' capability to suppress their urges to engage in compulsive behaviors.

\section{CONCLUSION}

In the present work, we have reviewed the literature of task conflict, which manifests when several, contradictory task sets are activated simultaneously. The accumulating evidence aid portraying task conflict as a unique feature of cognitive control, which is distinct from other conflict types and results in specific neuronal and behavioral signatures. Task conflict has been shown to manifest under the Stroop task and additional tasks including task switching, object interference, and affordance tasks, and to be strongly related to the concept of stimulusdriven behaviors.

One final note should be mentioned. Despite the ample evidence for the manifestation of different conflict types in the Stroop and Stroop-like tasks (Kornblum, 1992, 1994; Kornblum and Lee, 1995), some researchers who are interested in Stroop interference seem to neglect that it goes beyond response competition or ignore the (non-word) neutral condition and use the RT difference between congruent and incongruent conditions as a sole measure. These practices may lead to overlooking some important aspects of cognitive control and 
result in misinterpretations of certain results (Augustinova et al., 2018; Hershman and Henik, in press). To avoid such errors, the contribution of task conflict to the general Stroop conflict should be regularly considered.

\section{AUTHOR CONTRIBUTIONS}

All authors listed have made a substantial, direct and intellectual contribution to the work, and approved it for publication.

\section{REFERENCES}

Aarts, E., Roelofs, A., and van Turennout, M. (2009). Attentional control of task and response in lateral and medial frontal cortex: brain activity and reaction time distributions. Neuropsychologia 47, 2089-2099. doi: 10.1016/j. neuropsychologia.2009.03.019

Allport, A., and Wylie, G. (2000). "Task switching, stimulus-response bindings, and negative priming" in Control of cognitive processes: Attention and performance XVIII. eds. S. Monsell and J. Driver (Cambridge, MA: MIT Press), $35-70$.

Augustinova, M., and Ferrand, L. (2014). Automaticity of word reading: evidence from the semantic Stroop paradigm. Curr. Dir. Psychol. Sci. 23, 343-348. doi: $10.1177 / 0963721414540169$

Augustinova, M., Silvert, L., Spatola, N., and Ferrand, L. (2018). Further investigation of distinct components of Stroop interference and of their reduction by short response-stimulus intervals. Acta Psychol. 189, 54-62. doi: 10.1016/j.actpsy.2017.03.009

Banich, M. T. (2009). Executive function: the search for an integrated account. Curr. Dir. Psychol. Sci. 18, 89-94. doi: 10.1111/j.1467-8721.2009.01615.x

Barch, D. M., and Ceaser, A. (2012). Cognition in schizophrenia: core psychological and neural mechanisms. Trends Cogn. Sci. 16, 27-34. doi: 10.1016/j. tics.2011.11.015

Beatty, J., and Lucero-Wagoner, B. (2000). "The pupillary system” in Handbook of psychophysiology. Vol. 2, eds. J. T. Cacioppo, L. G. Tassinary, and G. G. Berntson (Cambride, MA: Cambridge University Press), 142-162.

Beauchamp, M. S., and Martin, A. (2007). Grounding object concepts in perception and action: evidence from fMRI studies of tools. Cortex 43, 461-468. doi: 10.1016/S0010-9452(08)70470-2

Bench, C., Frith, C. D., Grasby, P. M., Friston, K. J., Paulesu, E., Frackowiak, R. S. J., et al. (1993). Investigations of the functional anatomy of attention using the Stroop test. Neuropsychologia 31, 907-922. doi: 10.1016/00283932(93) $90147-\mathrm{R}$

Bloom, P. (2002). How children learn the meanings of words. Cambridge, MA: MIT Press.

Botvinick, M. M., Braver, T. S., Barch, D. M., Carter, C. S., and Cohen, J. D. (2001). Conflict monitoring and cognitive control. Psychol. Rev. 108, 624- 652. doi: $10.1037 / 0033-295 X .108 .3 .624$

Botvinick, M. M., Cohen, J. D., and Carter, C. S. (2004). Conflict monitoring and anterior cingulate cortex: an update. Trends Cogn. Sci. 8, 539-546. doi: 10.1016/j.tics.2004.10.003

Botvinick, M., Nystrom, L. E., Fissell, K., Carter, C. S., and Cohen, J. D. (1999). Conflict monitoring versus selection-for-action in anterior cingulate cortex. Nature 402, 179-181.

Bouton, M. E. (2004). Context and behavioral processes in extinction. Learn. Mem. 11, 485-494. doi: 10.1101/lm.78804

Braver, T. S. (2012). The variable nature of cognitive control: a dual-mechanisms framework. Trends Cogn. Sci. 16, 106-113. doi: 10.1016/j.tics.2011.12.010

Braver, T. S., Barch, D. M., Gray, J. R., Molfese, D. L., and Snyder, A. (2001). Anterior cingulate cortex and response conflict: effects of frequency, inhibition and errors. Cereb. Cortex 11, 825-836. doi: 10.1093/cercor/11.9.825

Braver, T. S., Gray, J. R., and Burgess, G. C. (2007). "Explaining the many varieties of working memory variation: dual mechanisms of cognitive control" in Variation in working memory. eds. C. J. A. Conway, M. Kane, A. Miyake, and J. Towse (Oxford: Oxford University Press).

\section{FUNDING}

The authors are supported by the Israel Science Foundation (grant no. 31/3431) and the National Institute for Psychobiology, Israel (21517-18b).

\section{ACKNOWLEDGMENTS}

We thank Hadar Naftalovich for her useful input on this article.

Braverman, A., Berger, A., and Meiran, N. (2014). The hierarchy of task decision and response selection: a task-switching event related potentials study. Brain Cogn. 88, 35-42. doi: 10.1016/j.bandc.2014.04.006

Braverman, A., and Meiran, N. (2010). Task conflict effect in task switching. Psychol. Res. 74, 568-578. doi: 10.1007/s00426-010-0279-2

Brosnan, M. B., and Wiegand, I. (2017). The dorsolateral prefrontal cortex, a dynamic cortical area to enhance top-down attentional control. J. Neurosci. 37, 3445-3446. doi: 10.1523/JNEUROSCI.0136-17.2017

Brown, G. G., Kindermann, S. S., Siegle, G. J., Granholm, E., Wong, E. C., and Buxton, R. B. (1999). Brain activation and pupil response during covert performance of the Stroop Color Word task. J. Int. Neuropsychol. Soc. 5, 308-319. doi: 10.1017/S1355617799544020

Bugg, J. M., and Braver, T. S. (2016). Proactive control of irrelevant task rules during cued task switching. Psychol. Res. 80, 860-876. doi: 10.1007/ s00426-015-0686-5

Bush, G., Luu, P., and Posner, M. I. (2000). Cognitive and emotional influences in anterior cingulate cortex. Trends Cogn. Sci. 4, 215-222. doi: 10.1016/ S1364-6613(00)01483-2

Carter, C. S., Botvinick, M. M., and Cohen, J. D. (1999). The contribution of the anterior cingulate cortex to executive processes in cognition. Rev. Neurosci. 10, 49-58. doi: 10.1515/REVNEURO.1999.10.1.49

Carter, C. S., Braver, T. S., Barch, D. M., Botvinick, M. M., Noll, D., and Cohen, J. D. (1998). Anterior cingulate cortex, error detection, and the online monitoring of performance. Science 280, 747-749. doi: 10.1126/ science. 280.5364 .747

Carter, C. S., Mintun, M., and Cohen, J. D. (1995). Interference and facilitation effects during selective attention: an H215O PET study of Stroop task performance. NeuroImage 2, 264-272. doi: 10.1006/nimg.1995.1034

Carter, C. S., and Van Veen, V. (2007). Anterior cingulate cortex and conflict detection: an update of theory and data. Cogn. Affect. Behav. Neurosci. 7, 367-379. doi: 10.3758/CABN.7.4.367

Creem-Regehr, S. H., and Lee, J. N. (2005). Neural representations of graspable objects: are tools special? Cogn. Brain Res. 22, 457-469. doi: 10.1016/j. cogbrainres.2004.10.006

De Jong, R., Liang, C.-C., and Lauber, E. (1994). Conditional and unconditional automaticity: a dual-process model of effects of spatial stimulus-response correspondence. J. Exp. Psychol. Hum. Percept. Perform. 20, 731-750. doi: 10.1037/0096-1523.20.4.731

De Pisapia, N., and Braver, T. S. (2006). A model of dual control mechanisms through anterior cingulate and prefrontal cortex interactions. Neurocomputing 69, 1322-1326. doi: 10.1016/j.neucom.2005.12.100

Desmet, C., Fias, W., Hartstra, E., and Brass, M. (2011). Errors and conflict at the task level and the response level. J. Neurosci. 31, 1366-1374. doi 10.1523/JNEUROSCI.5371-10.2011

Diamond, A. (2013). Executive functions. Annu. Rev. Psychol. 64, 135-168. doi: 10.1146/annurev-psych-113011-143750

Diesendruck, G., and Bloom, P. (2003). How specific is the shape bias? Child Dev. 74, 168-178. doi: 10.1111/1467-8624.00528

Egner, T., and Hirsch, J. (2005). Cognitive control mechanisms resolve conflict through cortical amplification of task-relevant information. Nat. Neurosci. 8, 1784-1790. doi: 10.1038/nn1594

Eimer, M. (1995). Stimulus-response compatibility and automatic response activation: evidence from psychophysiological studies. J. Exp. Psychol. Hum. Percept. Perform. 21, 837-854. doi: 10.1037/0096-1523.21.4.837 
Elchlepp, H., Rumball, F., and Lavric, A. (2013). A brain-potential correlate of task-set conflict. Psychophysiology 50, 314-323. doi: 10.1111/psyp.12015

Ellis, R., and Tucker, M. (2000). Micro-affordance: the potentiation of components of action by seen objects. Br. J. Psychol. 91, 451-471. doi: 10.1348/ 000712600161934

Entel, O., Tzelgov, J., Bereby-Meyer, Y., and Shahar, N. (2015). Exploring relations between task conflict and informational conflict in the Stroop task. Psychol. Res. 79, 913-927. doi: 10.1007/s00426-014-0630-0

Ganor-Moscovitz, N., Weinbach, N., Canetti, L., and Kalanthroff, E. (2018). The effect of food-related stimuli on inhibition in high vs. low restrained eaters. Appetite 131, 53-58. doi: 10.1016/j.appet.2018.08.037

Gibbons, H., and Stahl, J. (2008). Early activity in the lateralized readiness potential suggests prime-response retrieval as a source of negative priming. Exp. Psychol. 55, 164-172. doi: 10.1027/1618-3169.55.3.164

Gibson, J. J. (1979). The ecology approach to visual perception: Classic edition. Boston: Houghton Mifflin.

Gillan, C. M., Morein-Zamir, S., Urcelay, G. P., Sule, A., Voon, V., ApergisSchoute, A. M., et al. (2014). Enhanced avoidance habits in obsessivecompulsive disorder. Biol. Psychiatry 75, 631-638. doi: 10.1016/j.biopsych. 2013.02.002

Gillan, C. M., Otto, A. R., Phelps, E. A., and Daw, N. D. (2015). Model-based learning protects against forming habits. Cogn. Affect. Behav. Neurosci. 15, 523-536. doi: 10.3758/s13415-015-0347-6

Goldfarb, L., and Henik, A. (2007). Evidence for task conflict in the Stroop effect. J. Exp. Psychol. Hum. Percept. Perform. 33, 1170-1176. doi: 10.1037/00961523.33.5.1170

Graham, C. H., and Gagné, R. M. (1940). The acquisition, extinction, and spontaneous recovery of a conditioned operant response. J. Exp. Psychol. 26, 251-280.

Grandjean, J., d'Ostilio, K., Fias, W., Phillips, C., Balteau, E., Degueldre, C., et al. (2013). Exploration of the mechanisms underlying the ISPC effect: evidence from behavioral and neuroimaging data. Neuropsychologia 51, 1040-1049. doi: 10.1016/j.neuropsychologia.2013.02.015

Grandjean, J., D’Ostilio, K., Phillips, C., Balteau, E., Degueldre, C., Luxen, A., et al. (2012). Modulation of brain activity during a Stroop inhibitory task by the kind of cognitive control required. PLoS One 7:e41513. doi: 10.1371/ journal.pone.0041513

Guttman, N. (1953). Operant conditioning, extinction, and periodic reinforcement in relation to concentration of sucrose used as reinforcing agent. J. Exp. Psychol. 46, 213-224. doi: 10.1037/h0061893

Hasshim, N., and Parris, B. A. (2015). Assessing stimulus-stimulus (semantic) conflict in the Stroop task using saccadic two-to-one color response mapping and preresponse pupillary measures. Atten. Percept. Psychophys. 77, 2601-2610. doi: $10.3758 /$ s13414-015-0971-9

Hershman, R., and Henik, A. (in press). Dissociation between reaction time and pupil dilation in the Stroop task. J. Exp. Psychol. Learn. Mem. Cogn. doi: $10.1037 / \mathrm{xlm} 0000690$

Hochman, S., Henik, A., and Kalanthroff, E. (2018). Stopping at a red light: recruitment of inhibitory control by environmental cues. PLoS One 13:e0196199. doi: 10.1371/journal.pone.0196199

Kagan, J., and Lemkin, J. (1961). Form, color, and size in children's conceptual behavior. Child Dev. 32, 25-28.

Kahneman, D., and Beatty, J. (1966). Pupil diameter and load on memory. Science 154, 1583-1585.

Kalanthroff, E., Anholt, G. E., Keren, R., and Henik, A. (2013a). What should I (not) do? Control over irrelevant tasks in obsessive-compulsive disorder patients. Clin Neuropsychiatry 10, 61-64.

Kalanthroff, E., Avnit, A., Henik, A., Davelaar, E. J., and Usher, M. (2015). Stroop proactive control and task conflict are modulated by concurrent working memory load. Psychon. Bull. Rev. 22, 869-875. doi: 10.3758/s13423-014-0735-x

Kalanthroff, E., Davelaar, E. J., Henik, A., Goldfarb, L., and Usher, M. (2018a). Task conflict and proactive control: a computational theory of the Stroop task. Psychol. Rev. 125, 59-82. doi: 10.1037/rev0000083

Kalanthroff, E., Goldfarb, L., and Henik, A. (2013b). Evidence for interaction between the stop signal and the Stroop task conflict. J. Exp. Psychol. Hum. Percept. Perform. 39:579. doi: 10.1037/a0027429

Kalanthroff, E., Goldfarb, L., Usher, M., and Henik, A. (2013c). Stop interfering: Stroop task conflict independence from informational conflict and interference. Q. J. Exp. Psychol. 66, 1356-1367. doi: 10.1080/17470218.2012.741606
Kalanthroff, E., and Henik, A. (2013). Individual but not fragile: individual differences in task control predict Stroop facilitation. Conscious. Cogn. 22, 413-419. doi: 10.1016/j.concog.2013.01.010

Kalanthroff, E., and Henik, A. (2014). Preparation time modulates pro-active control and enhances task conflict in task switching. Psychol. Res. 78, 276-288. doi: 10.1007/s00426-013-0495-7

Kalanthroff, E., Henik, A., Simpson, H. B., Todder, D., and Anholt, G. E. (2017). To do or not to do? Task control deficit in obsessive-compulsive disorder. Behav. Ther. 48, 603-613. doi: 10.1016/j.beth.2017.01.004

Kalanthroff, E., Steinman, S. A., Schmidt, A. B., Campeas, R., and Simpson, H. B. (2018b). Piloting a personalized computerized inhibitory training program for individuals with obsessive-compulsive disorder. Psychother. Psychosom. 87, 52-54. doi: 10.1159/000481199

Kerns, J. G., Cohen, J. D., MacDonald, A. W., Cho, R. Y., Stenger, V. A., and Carter, C. S. (2004). Anterior cingulate conflict monitoring and adjustments in control. Science 303, 1023-1026. doi: 10.1126/science.1089910

Kinoshita, S., De Wit, B., and Norris, D. (2017). The magic of words reconsidered: investigating the automaticity of reading color-neutral words in the Stroop task. J. Exp. Psychol. Learn. Mem. Cogn. 43, 369-384. doi: 10.1037/xlm0000311

Koch, I., and Allport, A. (2006). Cue-based preparation and stimulus-based priming of tasks in task switching. Mem. Cogn. 34, 433-444. doi: 10.3758/ BF03193420

Kornblum, S. (1992). "Dimensional overlap and dimensional relevance in stimulus-response and stimulus-stimulus compatibility" in Advances in psychology. Vol. 87, eds. G. E. Stelmach and J. Requin (Oxford, England, North-Holland), 743-777.

Kornblum, S. (1994). The way irrelevant dimensions are processed depends on what they overlap with: the case of Stroop-and Simon-like stimuli. Psychol. Res. 56, 130-135. doi: 10.1007/BF00419699

Kornblum, S., and Lee, J.-W. (1995). Stimulus-response compatibility with relevant and irrelevant stimulus dimensions that do and do not overlap with the response. J. Exp. Psychol. Hum. Percept. Perform. 21, 855-875.

La Heij, W., and Boelens, H. (2011). Color-object interference: further tests of an executive control account. J. Exp. Child Psychol. 108, 156-169. doi: 10.1016/j.jecp.2010.08.007

La Heij, W., Boelens, H., and Akerboom, S. P. (2013). Color-picture interference in children: effects of spatial and temporal segregation of color and form. Percept. Mot. Skills 116, 78-90. doi: 10.2466/27.10.24.PMS.116.1.78-90

La Heij, W., Boelens, H., and Kuipers, J.-R. (2010). Object interference in children's colour and position naming: lexical interference or task-set competition? Lang. Cogn. Process. 25, 568-588. doi: 10.1080/01690960903381174

Laeng, B., Ørbo, M., Holmlund, T., and Miozzo, M. (2011). Pupillary stroop effects. Cogn. Process. 12, 13-21. doi: 10.1007/s10339-010-0370-z

Laeng, B., Sirois, S., and Gredebäck, G. (2012). Pupillometry: a window to the preconscious? Perspect. Psychol. Sci. 7, 18-27. doi: 10.1177/ 1745691611427305

Levin, Y., and Tzelgov, J. (2014). Conflict components of the Stroop effect and their "control." Front. Psychol. 5:463. doi: 10.3389/fpsyg.2014.00463

Levin, Y., and Tzelgov, J. (2016a). Contingency learning is not affected by conflict experience: evidence from a task conflict-free, item-specific Stroop paradigm. Acta Psychol. 164, 39-45. doi: 10.1016/j.actpsy.2015.12.009

Levin, Y., and Tzelgov, J. (2016b). What Klein's "semantic gradient" does and does not really show: decomposing Stroop interference into task and informational conflict components. Front. Psychol. 7:249. doi: 10.3389/fpsyg.2016.00249

MacDonald, A. W., Cohen, J. D., Stenger, V. A., and Carter, C. S. (2000). Dissociating the role of the dorsolateral prefrontal and anterior cingulate cortex in cognitive control. Science 288, 1835-1838. doi: 10.1126/ science. 288.5472 .1835

MacLeod, C. M. (1991). Half a century of research on the Stroop effect: an integrative review. Psychol. Bull. 109, 163-203. doi: 10.1037/0033-2909.109.2.163

MacLeod, C. M., and MacDonald, P. A. (2000). Interdimensional interference in the Stroop effect: uncovering the cognitive and neural anatomy of attention. Trends Cogn. Sci. 4, 383-391. doi: 10.1016/S1364-6613(00)01530-8

Makris, S., Grant, S., Hadar, A. A., and Yarrow, K. (2013). Binocular vision enhances a rapidly evolving affordance priming effect: behavioural and TMS evidence. Brain Cogn. 83, 279-287. doi: 10.1016/j.bandc.2013.09.004

Martin, A., Wiggs, C. L., Ungerleider, L. G., and Haxby, J. V. (1996). Neural correlates of category-specific knowledge. Nature 379, 649-652. doi: $10.1038 / 379649 \mathrm{a} 0$ 
Milham, M. P., Erickson, K. I., Banich, M. T., Kramer, A. F., Webb, A., Wszalek, T., et al. (2002). Attentional control in the aging brain: insights from an fMRI study of the stroop task. Brain Cogn. 49, 277-296. doi: 10.1006/brcg.2001.1501

Monsell, S. (2003). Task switching. Trends Cogn. Sci. 7, 134-140. doi: 10.1016/ S1364-6613(03)00028-7

Monsell, S., Taylor, T. J., and Murphy, K. (2001). Naming the color of a word: is it responses or task sets that compete? Mem. Cogn. 29, 137-151. doi: 10.3758/BF03195748

Mordkoff, J. T. (1996). "Selective attention and internal constraints: there is more to the flanker effect than biased contingencies" in Converging operations in the study of visual selective attention. eds. A. F. Kramer, M. G. H. Coles, and G. D. Logan (Washington, DC: American Psychological Association), 483-502.

Moutsopoulou, K., and Waszak, F. (2012). Across-task priming revisited: response and task conflicts disentangled using ex-Gaussian distribution analysis. J. Exp. Psychol. Hum. Percept. Perform. 38, 367-374. doi: 10.1037/a0025858

Osman, A., Bashore, T. R., Coles, M. G. H., Donchin, E., and Meyer, D. E. (1992). On the transmission of partial information: inferences from movementrelated brain potentials. J. Exp. Psychol. Hum. Percept. Perform. 18, 217-232. doi: 10.1037/0096-1523.18.1.217

Parris, B. A. (2014). Task conflict in the Stroop task: when Stroop interference decreases as Stroop facilitation increases in a low task conflict context. Front. Psychol. 5:1182. doi: 10.3389/fpsyg.2014.01182

Pellicano, A., Iani, C., Borghi, A. M., Rubichi, S., and Nicoletti, R. (2010). Simon-like and functional affordance effects with tools: the effects of object perceptual discrimination and object action state. Q. J. Exp. Psychol. 63, 2190-2201. doi: 10.1080/17470218.2010.486903

Perlman, A., and Tzelgov, J. (2006). Interactions between encoding and retrieval in the domain of sequence-learning. J. Exp. Psychol. Learn. Mem. Cogn. 32, 118-130. doi: 10.1037/0278-7393.32.1.118

Phillips, J. C., and Ward, R. (2002). SR correspondence effects of irrelevant visual affordance: time course and specificity of response activation. Vis. Cogn. 9, 540-558. doi: 10.1080/13506280143000575

Prevor, M. B., and Diamond, A. (2005). Color-object interference in young children: a Stroop effect in children $3 \frac{1}{2}-6 \frac{1}{2}$ years old. Cogn. Dev. 20, 256-278. doi: 10.1016/j.cogdev.2005.04.001

Proverbio, A. M., Adorni, R., and D'aniello, G. E. (2011). $250 \mathrm{~ms}$ to code for action affordance during observation of manipulable objects. Neuropsychologia 49, 2711-2717. doi: 10.1016/j.neuropsychologia.2011.05.019

Proverbio, A. M., Azzari, R., and Adorni, R. (2013). Is there a left hemispheric asymmetry for tool affordance processing? Neuropsychologia 51, 2690-2701. doi: 10.1016/j.neuropsychologia.2013.09.023

Rescorla, R. A. (1993). Inhibitory associations between S and R in extinction. Anim. Learn. Behav. 21, 327-336. doi: 10.3758/BF03197998

Reuss, H., Kiesel, A., Kunde, W., and Hommel, B. (2011). Unconscious activation of task sets. Conscious. Cogn. 20, 556-567. doi: 10.1016/j.concog.2011.02.014

Righi, S., Orlando, V., and Marzi, T. (2014). Attractiveness and affordance shape tools neural coding: insight from ERPs. Int. J. Psychophysiol. 91, 240-253. doi: 10.1016/j.ijpsycho.2014.01.003

Robbins, T. W., Gillan, C. M., Smith, D. G., de Wit, S., and Ersche, K. D. (2012). Neurocognitive endophenotypes of impulsivity and compulsivity: towards dimensional psychiatry. Trends Cogn. Sci. 16, 81-91. doi: 10.1016/j.tics.2011.11.009

Rogers, R. D., and Monsell, S. (1995). Costs of a predictible switch between simple cognitive tasks. J. Exp. Psychol. Gen. 124, 207-231. doi: 10.1037/ 0096-3445.124.2.207

Rothermund, K., Wentura, D., and De Houwer, J. (2005). Retrieval of incidental stimulus-response associations as a source of negative priming. J. Exp. Psychol. Learn. Mem. Cogn. 31, 482-495. doi: 10.1037/0278-7393.31.3.482

Schmidt, J. R., and Besner, D. (2008). The Stroop effect: why proportion congruent has nothing to do with congruency and everything to do with contingency. J. Exp. Psychol. Learn. Mem. Cogn. 34, 514-523. doi: 10.1037/ 0278-7393.34.3.514

Schmidt, J. R., Crump, M. J. C., Cheesman, J., and Besner, D. (2007). Contingency learning without awareness: evidence for implicit control. Conscious. Cogn. 16, 421-435. doi: 10.1016/j.concog.2006.06.010

Schneider, D. W. (2015). Attentional control of response selection in task switching. J. Exp. Psychol. Hum. Percept. Perform. 41, 1315-1324. doi: 10.1037/ xhp0000091
Schuch, S., Dignath, D., Steinhauser, M., and Janczyk, M. (2019). Monitoring and control in multitasking. Psychon. Bull. Rev. 26, 222-240. doi: 10.3758/ s13423-018-1512-z

Shahar, N., and Meiran, N. (2015). Differential contribution of task conflicts to task switch cost and task mixing cost in alternating runs and cued task-switching: evidence from ex-gaussian modeling of reaction time distributions. Psychol. Res. 79, 259-266. doi: 10.1007/s00426-014-0569-1

Shichel, I., and Tzelgov, J. (2018). Modulation of conflicts in the Stroop effect. Acta Psychol. 189, 93-102. doi: 10.1016/j.actpsy.2017.10.007

Siegel, A. W., and Vance, B. J. (1970). Visual and haptic dimensional preference: a developmental study. Dev. Psychol. 3, 264-266. doi: 10.1037/h0029584

Siegle, G. J., Ichikawa, N., and Steinhauer, S. (2008). Blink before and after you think: blinks occur prior to and following cognitive load indexed by pupillary responses. Psychophysiology 45, 679-687. doi: 10.1111/j.14698986.2008.00681.x

Siegle, G. J., Steinhauer, S. R., and Thase, M. E. (2004). Pupillary assessment and computational modeling of the Stroop task in depression. Int. J. Psychophysiol. 52, 63-76. doi: 10.1016/j.ijpsycho.2003.12.010

Sirois, S., and Brisson, J. (2014). Pupillometry. Wiley Interdiscip. Rev. Cogn. Sci. 5, 679-692. doi: 10.1002/wcs.1323

Skinner, B. F. (1953). Science and human behavior. New York: Macmillan.

Starreveld, P. A., and La Heij, W. (2017). Picture-word interference is a Stroop effect: a theoretical analysis and new empirical findings. Psychon. Bull. Rev. 24, 721-733. doi: 10.3758/s13423-016-1167-6

Steinhauser, M., and Hübner, R. (2009). Distinguishing response conflict and task conflict in the Stroop task: evidence from ex-Gaussian distribution analysis. J. Exp. Psychol. Hum. Percept. Perform. 35, 1398-1412. doi: 10.1037/ a0016467

Stroop, J. R. (1935). Studies of interference in serial verbal reactions. J. Exp. Psychol. 18, 643-662. doi: 10.1037/h0054651

Tipper, S. P., Paul, M. A., and Hayes, A. E. (2006). Vision-for-action: the effects of object property discrimination and action state on affordance compatibility effects. Psychon. Bull. Rev. 13, 493-498. doi: 10.3758/ BF03193875

Tucker, M., and Ellis, R. (1998). On the relations between seen objects and components of potential actions. J. Exp. Psychol. Hum. Percept. Perform. 24, 830-846. doi: 10.1037/0096-1523.24.3.830

Tucker, M., and Ellis, R. (2004). Action priming by briefly presented objects. Acta Psychol. 116, 185-203. doi: 10.1016/j.actpsy.2004.01.004

Tzelgov, J., Henik, A., and Berger, J. (1992). Controlling Stroop effects by manipulating expectations for color words. Mem. Cogn. 20, 727-735. doi: 10.3758/BF03202722

Vainio, L., Ellis, R., and Tucker, M. (2007). The role of visual attention in action priming. Q. J. Exp. Psychol. 60, 241-261. doi: 10.1080/ 17470210600625149

Vainio, L., Symes, E., Ellis, R., Tucker, M., and Ottoboni, G. (2008). On the relations between action planning, object identification, and motor representations of observed actions and objects. Cognition 108, 444-465. doi: 10.1016/j.cognition.2008.03.007

Valle-Inclán, F. (1996). The locus of interference in the Simon effect: an ERP study. Biol. Psychol. 43, 147-162. doi: 10.1016/0301-0511(95)05181-3

van der Wel, P., and van Steenbergen, H. (2018). Pupil dilation as an index of effort in cognitive control tasks: a review. Psychon. Bull. Rev. 25, 2005-2015. doi: 10.3758/s13423-018-1432-y

Waszak, F., Hommel, B., and Allport, A. (2003). Task-switching and long-term priming: role of episodic stimulus-task bindings in task-shift costs. Cogn. Psychol. 46, 361-413. doi: 10.1016/S0010-0285(02)00520-0

Conflict of Interest Statement: The authors declare that the research was conducted in the absence of any commercial or financial relationships that could be construed as a potential conflict of interest.

Copyright (c) 2019 Littman, Keha and Kalanthroff. This is an open-access article distributed under the terms of the Creative Commons Attribution License (CC BY). The use, distribution or reproduction in other forums is permitted, provided the original author(s) and the copyright owner(s) are credited and that the original publication in this journal is cited, in accordance with accepted academic practice. No use, distribution or reproduction is permitted which does not comply with these terms. 